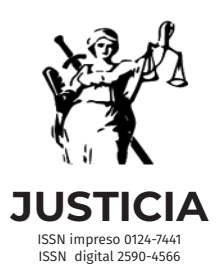

\title{
Comisión interamericana y los estados que denuncian la convención americana y la carta de la OEA
}

\section{Interamerican commission and the states denouncing the american convention and the OAS charter}

\author{
Eduardo Gabriel Osorio Sánchez \\ Universidad Francisco de Paula Santander \\ eduardogabrieos@ufps.edu.co
}

\author{
Liany Yetzira Hernández Granados \\ Universidad Francisco de Paula Santander \\ lianyyetzirahg@ufps.edu.co
}

Recibido: 9 de enero de 2020 / Aceptado: 16 de marzo de 2020 https://doi.org/10.17081/just.25.37.4344

\begin{abstract}
Resumen
Objetivo: Establecer las competencias que la Comisión Interamericana de Derechos Humanos tendría frente a un Estado que ha denunciado la Convención Americana y la Carta de la OEA una vez ésta denuncia entra en vigor. Método: Se acudió a una Metodología con enfoque cualitativo, con desarrollo del método hermenéutico que comprendió el análisis de información primaria compuesta por la normativa del Sistema Interamericano de Derechos Humanos y la jurisprudencia proferida por la Corte Interamericana, así como informes de la Comisión Interamericana de Derechos Humanos. Así mismo, se analizó información secundaria, compuesta por libros, capítulos de libro, artículos de revistas académicas, entre otros, que se consideraron determinantes en la investigación. Resultados: La Comisión Interamericana de Derechos Humanos seguiría teniendo competencias de garantía de los Derechos Humanos respecto de un Estado denunciante de la Convención Americana y la Carta de la OEA, lo cual es importante de cara a la construcción de un espacio de democracia en las Américas. Conclusiones: Si bien la salida de un Estado americano de la OEA sería un fracaso en la construcción de democracia a nivel regional, no implica automáticamente que éste Estado quede al margen de obligaciones en materia de Derechos Humanos en el sistema regional, ni la pérdida de competencia de la Comisión Interamericana en la protección y garantía de estos derechos.
\end{abstract}

PALABRAs Clave: comisión Interamericana de derechos humanos, competencia, convención americana sobre derechos humanos, derechos humanos, organización de estados americanos.

Abstract

Objective: To establish the powers that the Inter-American Commission on Human Rights would have vis-à-vis a State that has denounced the American Convention and the OAS Charter once this denunciation comes into force. Method: A methodology with a qualitative approach was used, with the hermeneutic method developed, which included the analysis of primary information made up of the regulations that make up the Inter-American Human Righ+ts System and the jurisprudence issued by the Inter-American Court, as well as reports from the Inter-American Commission on Human Rights. Likewise, secondary information was analyzed, consisting of books, book chapters, academic journal articles, among others, which were considered decisive in the research. Results: The Inter-American Commission on Human Rights would continue to have competencies to guarantee human rights with respect to a State that denounces the American Convention and the OAS Charter, which is important for the construction of a space for democracy in the Americas. Conclusions: Although the departure of an American State from the OAS would be a failure in the construction of democracy at the regional level, it does not automatically imply that this State is left out of human rights obligations in the regional system, nor the loss of competence of the Inter-American Commission in the protection and guarantee of these rights

KEYWORDS: american convention on human rights, competition, human rights, inter-american commission on human rights, organization of american states.

\section{Como citar:}

Osorio Sánchez, E. G., \& Hernández Granados, L. Y. (2020). Comisión interamericana y los estados que denuncian la convención americana y la carta de la OEA. Justicia, 25(37), 185-200. https://doi.org/10.17081/just.25.37.4344 


\section{Introducción}

En el presente artículo se realiza una revisión de las competencias de la Comisión Interamericana frente a un Estado que denuncie efectivamente, tanto la Convención Americana de Derechos Humanos como la Carta de la OEA. Esta situación paradigmática y aparentemente improbable, no está lejos de la realidad en la que se encuentra actualmente la OEA con la permanencia o no de Venezuela en el sistema americano, debido a la denuncia que el presidente Nicolás Maduro presentó ante el Secretario General de la OEA el 27 de abril de 2017 y que con una suerte de decisión política, aun no termina de materializarse por el desistimiento que efectuare Juan Guaido como Presidente (e) de Venezuela, mediante comunicación remitida a esta organización internacional el 8 de febrero de 2019. Este escenario coloca a la región americana en una situación probable en la que un Estado deje finalmente de pertenecer a la OEA, así como incluso dejó de pertenecer como Estado parte de la Convención Americana.

La posible salida de Venezuela de la OEA, ha conllevado que Colombia haya elevado una solicitud de Opinión Consultiva a la Corte Interamericana, con el propósito de determinar las obligaciones internacionales que en materia de derechos humanos subsisten para un Estado que además de haber denunciado la $\mathrm{CADH}$, pretenda retirarse de la OEA, solicitud que se plantea en un escenario hipotético y sin hacer referencia a Venezuela, debido a los requisitos establecidos en la CADH para elevar este tipo de consultas, pero claramente direccionado a la posibilidad de que éste Estado finalmente se retire del organismo multilateral.

En este escenario probable, el artículo da respuesta a qué pasaría con las competencias de la Comisión Interamericana en materia de promoción y protección de derechos humanos, frente a un Estado que no sólo se retiró de la Convención Americana, sino que además ha denunciado efectivamente la Carta de la OEA.

La respuesta es importante de cara al proceso de construcción democrática que los Estados Americanos visualizaron a partir de la Carta de la OEA en 1948 y el fortalecimiento de los Derechos Humanos en la región, con la Declaración Americana de Derechos y Deberes del Hombre y la Convención Americana de Derechos Humanos, ya que evidentemente, la salida de un país americano del tratado constitutivo -Carta de la OEA- es un fracaso en la construcción de este espacio americano de democracia y garantía de los derechos humanos.

De esta manera, en el presente artículo se establecen los efectos de denunciar la Convención Americana sobre Derechos Humanos y la Carta de la OEA, no solo respecto al sistema normativo interamericano de Derechos Humanos sino respecto de la competencia de la Comisión Interamericana como institución de garantía de estos derechos.

\section{Método}

El presente artículo está desarrollado mediante un enfoque cualitativo basado en el método hermenéutico, por medio del cual se interpretó y comprendió el material documental analizado. Para analizar la normativa internacional se utilizaron las reglas previstas en la Convención de Viena, acudiendo a sus diversos métodos de interpretación. En primer lugar, se atendió al sentido corriente que haya de atribuirse a sus términos, teniendo en cuenta su objeto y fin y, en segundo lugar, al método sistemático, es decir, entendiendo las normas como parte de un todo, para lo cual su significado y alcance se establece en función del sistema jurídico al cual pertenecen. 
La revisión documental objeto de la investigación comprendió la información primaria compuesta por la normativa del Sistema Interamericano de Derechos Humanos y la jurisprudencia proferida por la Corte Interamericana, así como informes de la Comisión Interamericana de Derechos Humanos. Así mismo, se analizó información secundaria, compuesta por libros, capítulos de libro, artículos de revistas académicas, entre otros, que se consideraron determinantes en la investigación.

\section{Resultados}

\section{La Comisión Interamericana de Derechos Humanos y el Sistema Interamericano}

La Comisión Interamericana de Derechos Humanos -en adelante CIDH o la Comisión- fue creada en la Quinta Reunión de Consulta de Ministros de Relaciones Exteriores en Santiago de Chile, efectuada entre los días 12 al 18 de agosto de 1959 (Secretaria General de la Organización de Estados Americanos, 1960). En la Resolución sobre Derechos Humanos, que como se verá más adelante se ocupa también de la Convención Americana y la Corte, se crea a la Comisión Interamericana y se establece que la misma estará conformada por siete miembros, elegidos de ternas enviadas por los Gobiernos, por el Consejo de la OEA y estaría encargada de promover el respeto de los Derechos Humanos (Secretaria General de la Organización de Estados Americanos, 1960).

La Comisión Interamericana entró en funcionamiento en el año 1960, cuando se aprobó su Estatuto el 25 de mayo de ese año y el 29 de junio se eligieron los primeros miembros de esta (Corte Interamericana de Derechos Humanos, 2012). A partir del año 1961 empezó a desarrollar sus funciones de monitoreo, realizando visitas a los Estados miembros de la OEA. Sin embargo, no sería hasta la modificación del Estatuto original en 1965, cuando la Segunda Conferencia Interamericana Extraordinaria que se celebró en Rio de Janeiro, Brasil, amplió las funciones de la CIDH y fue autorizada para recibir y procesar denuncias o peticiones de casos individuales, en los cuales se alegaran la violaciones de derechos humanos y como consecuencia de esta función, formular recomendaciones a los Estados miembros de la OEA (Corte Interamericana de Derechos Humanos, 2012). Dicha modificación se hizo efectiva en el periodo de sesiones de la CIDH de abril de 1966.

La Comisión Interamericana aparece mencionada por primera vez en la Carta de la Organización de Estados Americanos, reformada por el Protocolo de Buenos Aires que entró en vigencia en 1970, como uno de los órganos por medio de los cuales la Organización de Estados Americanos realizan sus fines, junto con la Asamblea General, la Reunión de Consulta de Ministros de Relaciones Exteriores, los Consejos, el Comité Jurídico Interamericano, la Secretaría General, las Conferencias Especializadas y los Organismos Especializados (Organización de Estados Americanos, 1948).

De esta manera, en su Capítulo XV, la Carta de la OEA se ocupa de la CIDH y establece que "Habrá una Comisión Interamericana de Derechos Humanos que tendrá, como función principal, la de promover la observancia y la defensa de los derechos humanos y de servir como órgano consultivo de la Organización en esta materia" y así mismo, se establece que será una Convención Americana sobre Derechos Humanos -en adelante CADH o Convención- la que determinará la "estructura, competencia y procedimiento de dicha Comisión, así como los de los otros órganos encargados de esa materia" (Organización de Estados Americanos, 1948).

Por su parte, mediante una Resolución proferida en la Novena Conferencia Internacional Americana, adelantada en la Ciudad de Bogotá en 1948, en el marco de aprobación de la Carta de la OEA, este organismo aprobó la Declaración de Derechos y Deberes del Hombre - en adelante Declaración Americana- el 30 
de abril de ese año, lo que puede ser considerado el inicio formal del Sistema Interamericano de Derechos Humanos (Corte Interamericana de Derechos Humanos, 2012). Este instrumento, a pesar de ser adoptado como declaración y no como tratado internacional, ha sido considerado por los organismos de garantía del sistema interamericano, CIDH y Corte Interamericana de Derechos Humanos -en adelante Corte Interamericana o Corte IDH- como fuente de obligaciones internacionales para los Estados parte de la OEA.

En efecto, la Corte IDH en su opinión consultiva OC-10/89, estableció que "Los Estados Miembros han entendido que la Declaración contiene y define aquellos derechos humanos esenciales a los que la Carta se refiere, de manera que no se puede interpretar y aplicar la Carta de la Organización en materia de derechos humanos, sin integrar las normas pertinentes de ella con las correspondientes disposiciones de la Declaración, como resulta de la práctica seguida por los órganos de la OEA", argumento que ha sido reiteradamente utilizado por la Corte Interamericana para la justiciabilidad directa del artículo 26 de la Convención, que se ocupa de los derechos Económicos, Sociales, Culturales y Ambientales (Opinión Consultiva OC-10/89, 1989) (Caso Lagos del Campo Vs. Perú (Excepciones Preliminares, Fondo, Reparaciones y Costas), 2017).

La Declaración Americana se encuentra compuesta por un preámbulo y 38 artículos en los que se enuncian y definen los derechos humanos protegidos, así como los deberes correspondientes. Dentro del listado de derechos se encuentran tanto derechos civiles y políticos como derechos económicos, sociales y culturales. Entre otros derechos se pueden encontrar el derecho a la vida (Art. I); igualdad ante la ley (Art. II); derecho a la protección a la honra, la reputación personal y la vida privada y familiar (Art. V); derecho a la inviolabilidad del domicilio (Art. IX); derecho a la educación (Art. XIII); derecho al trabajo y a una justa retribución (Art. XIV); derecho a la seguridad social (Art. XVI); derecho de justicia (Art. XVIII), entre otros.

La Convención Americana sobre Derechos Humanos tiene sus antecedentes en la Conferencia Interamericana celebrada en México en 1945, en la cual se realiza una recomendación al Comité Jurídico Interamericano de preparar un proyecto de declaración. Posteriormente, en la Quinta Reunión de Consulta de Ministros de Relaciones Exteriores en Santiago de Chile, se resuelve que el Consejo Interamericano de Jurisconsultos elabore un proyecto de Convención sobre Derechos Humanos, y se indica así mismo, que se elabore un proyecto sobre la creación de una "Corte Interamericana de Protección de los Derechos Humanos y de otros órganos adecuados para la tutela y observancia de los mismos". Se señaló que dichos proyectos se someterían a la Undécima Conferencia Interamericana (Secretaria General de la Organización de Estados Americanos, 1960).

Dicho proyecto presentado por parte del Consejo Interamericano de Jurisconsultos, se sometió al Consejo de la OEA, recibiendo de parte de los Estados y la Comisión Interamericana comentarios de reforma al mismo. En el año 1967 se presentó el proyecto reformado y se convocó a una Conferencia Especializada Interamericana sobre Derechos Humanos, los días 7 al 22 de noviembre de 1969 en la ciudad de San José de Costa Rica, siendo adoptada la Convención Americana el 21 de noviembre de 1969. La CADH entraría en vigor el 18 de julio de 1978.

Este sistema normativo de protección de derechos humanos en el sistema Americano se complementaría con la adopción y entrada en vigor del Protocolo de San Salvador (1999) y el protocolo relativo a la abolición de la pena de muerte, ambos adicionales a la Convención Americana y, las Convenciones Interamericanas para Prevenir y Sancionar la Tortura (1987); sobre la Desaparición Forzada de Personas (1996); para Prevenir, Sancionar y Erradicar la Violencia contra la Mujer (Convención de Belém do Pará) (1995); para la Eliminación de Todas las Formas de Discriminación contra las Personas con Discapacidad (2001); contra el Racismo, la Discriminación Racial y Formas Conexas de Intolerancia (2017); contra Toda Forma de Discriminación e Intolerancia y sobre la Protección de los Derechos Humanos de las Personas Mayores (2017). 
La entrada en vigor de la Convención Americana hizo necesario expedir un nuevo estatuto de la Comisión, aprobado en el Noveno periodo ordinario de sesiones de la Asamblea General de la OEA. Teniendo en cuenta que no todos los Estados parte de la OEA son parte de la Convención Americana, en el Estatuto se reflejan las competencias que tiene la Comisión, respecto a los mismos, dependiendo de que sean parte de la Convención Americana o no.

En este sentido, se observa que el artículo 1 del Estatuto define lo que debe entenderse por derechos humanos frente a la función de la CIDH de "promover la observancia y la defensa de los derechos humanos y servir como órgano consultivo de la Organización en esta materia" y para ello, recurre al catalogo de derechos tanto de la Convención Americana, respecto de los Estados parte, como a los derechos de la Declaración Americana, respecto de los Estados miembros de la OEA que no son parte de la CADH. Particularmente, respecto de su función de comunicaciones o peticiones individuales, el Estatuto alude al reglamento de la Comisión, para efectos del procedimiento que se debe seguir, dependiendo si se trata de una petición respecto de un Estado miembro de la Convención o no (Asamblea General de la OEA, 1979).

\section{La denuncia a la Convención Americana sobre Derechos Humanos y a la Carta de la OEA}

Los Estados parte de un tratado internacional pueden denunciarlo o retirarse del mismo. Si bien, como lo ha señalado la Corte IDH los tratados sobre derechos humanos no son tratados ordinarios, pues las obligaciones asumidas por los Estados no son respecto de otros Estados sino respecto de los individuos bajo su jurisdicción (Opinión Consultiva, 1982), esto no es impedimento para que se puedan dar por terminadas las obligaciones asumidas en virtud de un ellos (Sanchez Gomez, 2015).

Como lo establece el artículo 70 de la Convención de Viena, las consecuencias de la terminación de un tratado son (Organización de Naciones Unidas, 1969): a) eximir a las partes de la obligación de seguir cumpliendo el tratado; b) no afectar a ningún derecho, obligación o situación jurídica de las partes creados por la ejecución del tratado antes de su terminación. Para desvincularse de las obligaciones contraídas en virtud de los tratados, el Estado parte debe hacer la respectiva denuncia del tratado o seguir las disposiciones que se establecen en el artículo 56 de la Convención de Viena, en el caso de que el tratado no contenga disposiciones sobre la terminación, la denuncia o el retiro.

Al respecto se establece que un tratado que no contenga disposiciones sobre su terminación ni prevea la denuncia o el retiro de este, no podrá ser objeto de denuncia o de retiro a menos que: a) conste que fue intención de las partes admitir la posibilidad de denuncia o de retiro o b) el derecho de denuncia o de retiro pueda inferirse de la naturaleza del tratado. Así mismo, en este caso el Estado denunciante deberá notificar con doce meses, por lo menos, de antelación su intención de denunciar un tratado o de retirarse de él. (Organización de Naciones Unidas, 1969).

En el caso de la Convención Americana, se encuentra que su artículo 78 admite la posibilidad de denuncia de esta, sujetándola a ciertos requisitos (Organización de Estados Americanos, 1969):

$»$ La Convención sólo podrá ser denunciada después de la expiración de un plazo de cinco años a partir de la entrada en vigor de esta.

$\gg$ La Denuncia tendrá que hacerse mediante un preaviso de un año, notificando al Secretario General de la Organización, quien debe informar a las otras partes.

$\nRightarrow$ Dicha denuncia no tendrá por efecto desligar al Estado denunciante, de toda obligación de la Convención anterior a la fecha en la cual la denuncia produce efectos. 
Por su parte, la Carta de la OEA establece en su artículo 143 que los Estados miembros podrán hacer la respectiva denuncia mediante comunicación escrita a la Secretaria General, la cual comunicará en cada caso a los demás Estados las notificaciones de denuncia que reciba. La norma establece que transcurridos dos años a partir de la fecha en que la Secretaría General reciba una notificación de denuncia, la Carta cesará en sus efectos respecto del Estado denunciante, y éste quedará desligado de la Organización después de haber cumplido con las obligaciones emanadas de la Carta, sean estas de carácter económico, político o social (Organización de Estados Americanos, 1948).

Como se puede apreciar, tanto el tratado constitutivo de la Organización de Estados Americanos como la Convención Americana sobre Derechos Humanos, prevén la posibilidad de que los Estados parte denuncien el respectivo tratado internacional. Por un lado, Estados como Trinidad y Tobago y Venezuela han hecho efectiva la denuncia a la Convención Americana y el consecuente retiro de la competencia de la Corte Interamericana (Organización de Estados Americanos, 2014) y por el otro, Venezuela, denunció la Carta de la OEA (Presidente de la República Bolivariana de Venezuela, 2017), aunque no es clara la situación de este país con respecto a la OEA en el momento en el que se desarrolla este escrito, teniendo en cuenta que Juan Guaido como presidente interino de Venezuela en fecha 7 de marzo de 2019 -antes de que se cumpliera el plazo de dos años para que entre en vigor la denuncia- notificó al Secretario General de la OEA la decisión de dejar sin efecto la denuncia efectuada por el Presidente Nicolás Maduro, en fecha 28 de abril de 2017 (Presidente (e) de la República Bolivariana de Venezuela, 2019).

Frente a un escenario en el que se hace efectiva la denuncia de la Convención Americana es claro que se desligaría a los Estados miembros de la OEA de sus obligaciones en cuanto a ella. Sin embargo, dicha denuncia no significa que los demás instrumentos de protección de derechos humanos, tales como las convenciones interamericanas sobre derechos humanos en las que sea parte y la Declaración Americana, automáticamente dejen de ser vinculantes, ya que continuarían siendo miembros de la OEA (Lopez Hualde). En efecto, cada uno de las convenciones interamericanas cuentan con su propio mecanismo de ratificación o adhesión, así como el respectivo procedimiento de denuncia. Por lo tanto, las obligaciones previstas en las Convenciones Interamericanas y el catalogo de derechos humanos de la Declaración Americana siguen vigentes para los Estados parte.

Ahora bien, situación diferente sería el efecto que la denuncia de la CADH trae sobre su Protocolo de San Salvador, teniendo en cuenta que este instrumento es adicional a la Convención Americana. Aunque el Protocolo de San Salvador no contempla un mecanismo de denuncia, conforme a las reglas de la Convención de Viena, cuando un tratado no contenga disposiciones sobre su terminación ni prevea la denuncia o el retiro, no podrá ser objeto de denuncia a menos que el derecho de denuncia o de retiro pueda inferirse de la naturaleza del mismo (Organización de Naciones Unidas, 1969), situación que se presenta frente al Protocolo de San Salvador, cuando se denuncia la $\mathrm{CADH}$, siempre y cuando se cumpla con alguno de los supuestos que se derivan del artículo 56, que se dé aviso sobre esta situación, con al menos doce meses de anticipación.

Situación diferente sería si un Estado además de denunciar la CADH, denuncia la Carta de la OEA y ésta denuncia se hace efectiva, como lo puede llegar a ser el caso de Venezuela, ya que si bien la denuncia de la carta de la OEA no afectaría la vigencia de las obligaciones derivadas de las Convenciones Interamericanas sobre Derechos Humanos, debido a que cada una tiene su propio procedimiento de denuncia, si tendría consecuencias respecto de la Declaración Americana, ya que como lo ha señalado la Corte IDH, su obligatoriedad radica en su integración a las disposiciones de la Carta de la Organización de los Estados Americanos (Opinión Consultiva OC-10/89, 1989). 
De esta manera, respecto de un Estado que ha denunciado la Carta de la OEA y ésta entra en vigor, la Declaración Americana deja de ser fuente de obligaciones internacionales, ya que su valor como fuente debe ser entendida en el marco de la Carta de la OEA. En este sentido, vale la pena resaltar que la declaración “contiene y define aquellos derechos humanos esenciales a los que la Carta se refiere, de manera que no se puede interpretar y aplicar la Carta de la Organización en materia de derechos humanos, sin integrar las normas pertinentes de ella con las correspondientes disposiciones de la Declaración" (Opinión Consultiva OC-10/89, 1989).

Si bien se considera que, con la denuncia efectiva de la Carta de la OEA, las obligaciones derivadas de la Declaración Americana desaparecen para el Estado denunciante, se debe reseñar que el contenido obligacional derivado de la Declaración que se constituya como lus Cogens, sigue vigente a pesar de la denuncia efectuada. En efecto, conforme a lo establecido en el artículo 53 de la Convención de Viena, una norma es ius cogens cuando es “aceptada y reconocida por la comunidad internacional de Estados en su conjunto como norma que no admite acuerdo en contrario y que sólo puede ser modificada por una norma ulterior de derecho internacional general que tenga el mismo carácter" (Organización de Naciones Unidas, 1969).

Las normas que conforman el lus Cogens no admiten acuerdo en contrario, solo pueden ser modificadas por una norma ulterior de derecho internacional que tenga el mismo carácter, y todo tratado que se encuentre en oposición a estas es nulo (Organización de Naciones Unidas, 1969). Igualmente, dichos principios no se limitan al ámbito regional, siendo sus obligaciones erga omnes, "frente a toda la comunidad internacional", lo que descartaría a las obligaciones contraídas sólo en relación con algunos Estados, es decir, a las obligaciones que tienen única y exclusivamente una naturaleza convencional, su origen puede darse a partir de la costumbre o los tratados, y al no existir un catalogo preciso de las normas que conforman el ius cogens, la denuncia de un tratado no constituye una limitación a estas (Cebada Romero, 1967).

Por lo que resulta claro que el ius cogens conforma una excepción a la regla general del origen de las obligaciones internacionales en virtud del libre consentimiento de los Estados y del pacta sunt servanda, presentándose en oposición a la sustracción por la mera voluntad de los Estados, cuestión que se ratifica en el informe de la Comisión de Derecho Internacional en su $70^{\circ}$ periodo de sesiones, donde se señala que incluso cuando exista una reserva a una disposición de un tratado que refleje una norma imperativa de derecho internacional general (ius cogens) no se afecta el carácter vinculante de esa norma, que continuará siendo de aplicación (Comisión de Derecho Internacional, 2018). En conclusión, al no contemplarse como requisito de existencia y reconocimiento la codificación del ius cogens, su traducción en un texto internacional llámese tratado o convención, no limita su carácter de norma imperativa de derecho internacional general, y a su vez la denuncia del mismo, al igual que en el caso de las reservas no afecta el carácter vinculante del ius cogens, al ser inderogables, y su modificación solamente deriva de la contraposición con otra norma imperativa de derecho internacional general ulterior, teniendo en cuenta el carácter dinámico y evolutivo del concepto que entrañan dichas normas. Aun bajo el supuesto, que se aceptase la no obligatoriedad de una norma imperativa de derecho internacional general en razón a la denuncia de un tratado, su contenido material puede encontrarse en cualquier otra norma de carácter convencional o consuetudinario, teniendo en cuenta que constituyen un núcleo fundamental en el reconocimiento de los derechos humanos y la dignidad humana.

Por lo tanto, independientemente de que se denuncie la Convención Americana o la Carta de la OEA, el contenido de dichos instrumentos que sea reconocido como norma imperativa de derecho internacional general (ius cogens) conlleva la persistencia de las obligaciones respecto a las mismas, lo cual no obsta para reconocer que dicho Estado denunciante ya no se encontrará atado a los instrumentos de protección específicos del tratado respectivo ni a las normas del mismo que no estén reconocidas como ius cogens. 
Así, aunque es aceptable la no obligatoriedad de las normas de la Declaración Americana frente al Estado denunciante de la Carta de la OEA, su contenido obligacional puede seguir siendo considerado como materialmente vinculante para el Estado, en cuanto se encuentre en cualquier otra norma de carácter convencional o consuetudinario, que constituya un núcleo fundamental en el reconocimiento de los derechos humanos y la dignidad humana.

Llegados a este punto, habría que preguntarse qué consecuencias conllevaría la denuncia de la CADH y la Carta de la OEA frente a las funciones de la principal institución de garantía que prevé la Carta de la OEA para la promoción y protección de derechos humanos, la Comisión Interamericana de Derechos Humanos.

\section{Los efectos de la denuncia de la Carta de la OEA frente a las competencias de la CIDH}

En este apartado se determinará qué competencias puede seguir teniendo la Comisión Interamericana frente a un Estado que ha denunciado la Convención Americana y la Carta de la OEA. Para ello, es necesario analizar los factores de competencia de la Comisión frente al Estado denunciante de la Convención Americana y la Carta de la OEA, pero teniendo en cuenta que puede ser parte de las Convenciones Interamericanas sobre derechos humanos, debido a que no se presenta la denuncia automática de las mismas por retirarse del tratado constitutivo.

Para este propósito, se analizaran los factores de competencia de la Comisión Interamericana de derechos Humanos, en el siguiente orden: Ratione Materiae, Ratione Temporis, Ratione loci y Ratione Personae.

Por el factor Ratione Materiae, la CIDH tiene competencia para examinar peticiones individuales cuando en éstas se denuncien las violaciones de derechos humanos que se encuentren protegidas en la Convención Americana; la Declaración Americana o algún tratado interamericano que le otorgue competencia a la $\mathrm{CIDH}$, como lo pueden ser el Protocolo de San Salvador, la Convención Interamericana sobre Desaparición Forzada de Personas o la Convención de Belem do Pará, entre otras (Steiner \& Fuchs, 2019, pág. 932). Así mismo, la CIDH sería competente para recibir y examinar comunicaciones en las que un Estado parte alega que otro Estado ha violado los derechos humanos protegidos tanto en la Convención Interamericana contra toda forma de discriminación e intolerancia como en la Convención Interamericana sobre la protección de los derechos humanos de las personas mayores. Frente a este factor de competencia es importante resaltar además que, no solo se predica de la posibilidad de que la Comisión examine peticiones individuales e interestatales, sino que diversas convenciones interamericanas le otorgan competencia en razón a la materia, frente a otro tipo de funciones. Es el caso de la Convención Interamericana para prevenir y sancionar la tortura que le otorga competencia para recibir informes de los Estados parte y la Convención interamericana sobre la protección de los derechos humanos de las personas mayores, que establece la competencia de la CIDH de prestar asesoramiento y cooperación técnica.

Por lo tanto, las Convenciones Interamericanas que mantendrían la competencia de la CIDH frente a los Estados parte de éstas, para efectos de examinar peticiones individuales contra los Estados, serían: (i) la Convención Interamericana sobre Desaparición Forzada de Personas; (ii) la Convención Interamericana para Prevenir, Sancionar y Erradicar la Violencia contra la Mujer “Convención de Belem Do Pará”; (iii) la Convención Interamericana contra el Racismo, la discriminación racial y formas conexas de intolerancia; (iv) la Convención interamericana sobre la protección de los derechos humanos de las personas mayores y (v) la Convención Interamericana para la Eliminación de Todas las formas de Discriminación contra las Personas con Discapacidad. 
Frente a la competencia para recibir y examinar comunicaciones interestatales, se mantendría para los Estados parte de (i) la Convención Interamericana contra toda forma de discriminación e intolerancia y de (ii) la Convención Interamericana sobre la protección de los derechos humanos de las personas mayores.

Por su parte, en el caso de la Convención Interamericana para prevenir y sancionar la tortura, la competencia de la CIDH estaría limitada a recibir informes de los Estados parte.

En cuanto a la Competencia Ratione Temporis, esta se presenta cuando el asunto sometido a conocimiento de la Comisión ocurrió con posterioridad a la entrada en vigor en el Estado del tratado internacional cuya violación se pone en conocimiento y con anterioridad a la comunicación en caso de que se haya denunciado o retirado de alguna de las Convenciones Interamericanas que le otorgan competencia. Desde esta perspectiva, frente al Estado que haya denunciado la CADH y la Carta de la OEA, la CIDH tendría competencia por este factor, sólo respecto de hechos acaecidos mientras estuvo en vigor alguno de estos instrumentos internacionales.

Frente a la Competencia Ratione loci, este factor de competencia no tendría mayores problemas pues se encuentra asociado a que la CIDH solo podría revisar denuncias de violaciones a alguna de las anteriores Convenciones Interamericanas que le otorgan competencia, siempre y cuando hayan tenido lugar en la jurisdicción de algún Estado parte. Esta competencia se ha entendido que comprende a situaciones en las que el Estado ha ejercido su jurisdicción incluso por fuera de su territorio. En este sentido, la CIDH estableció la responsabilidad de los Estados Unidos por vulnerar la Declaración Americana y los instrumentos del derecho internacional de los refugiados, frente un caso de interdicción de balseros haitianos en alta mar, los cuales fueron repatriados por este Estado sin otorgarles la posibilidad de que pudieran reclamar su condición de refugiados (Informe n.o 51/96. Personas haitianas. Estados Unidos, 1997).

Finalmente, se tendría el factor Ratione Personae, factor que se ha dejado en último lugar, atendiendo a que es el que mayores dificultades generaría para la competencia derivada de las Convenciones Interamericanas a la CIDH, frente a un Estado que ha denunciado la Convención Americana y la Carta de la OEA. Para analizar dicha competencia se deben tener en cuenta las distintas funciones o competencias que otorgan las Convenciones Interamericanas a la CIDH y analizarlo conforme a los siguientes aspectos: (i) Quién presenta la petición, la denuncia interestatal o Informe respectivo; (ii) Quién o quiénes son las presuntas víctimas en caso de peticiones individuales y (iii) Cuál es el Estado Denunciado.

Respecto a la presentación de peticiones individuales y su posterior examen por la CIDH, se debe analizar quién presenta dicha petición. La misma puede ser presentada por personas, grupo de personas u ONG'S reconocidas por Estados parte de la OEA (Steiner \& Fuchs, 2019) contra el Estado que ha sido denunciado por violar los derechos de alguna de las Convenciones Interamericanas que otorgan ésta competencia a la Comisión (Convención Interamericana sobre Desaparición Forzada de Personas; Convención de Belém Do Pará; Convención Interamericana contra el Racismo, la discriminación racial y formas conexas de intolerancia; Convención interamericana sobre la protección de los derechos humanos de las personas mayores). Siempre que se cumplan estas condiciones de quien remite la petición, habría legitimación por activa para activar la competencia de la Comisión. Además, el artículo 24 del reglamento de la CIDH establece que "la Comisión podrá, motu proprio, iniciar la tramitación de una petición que contenga, a su juicio, los requisitos para tal fin" (Comisión Interamericana de derechos Humanos, 2009).

Así mismo, es necesario establecer quién o quiénes son las presuntas víctimas en caso de peticiones individuales. El Sistema de peticiones puede ser adelantado por personas que no necesariamente sean las presuntas víctimas de la violación de derechos humanos. Sin embargo, es importante reseñar que, por 
regla general, la presunta víctima deberá ser una persona física (natural) y no una jurídica, lo cual no obsta para que se haya admitido que las comunidades indígenas o tribales y los sindicatos (Opinión Consultiva OC-22/16, 2016), conforme al Protocolo de San Salvador, puedan ser considerados como presuntas víctimas. Bajo esta perspectiva, cualquiera que cumpla estas condiciones podría tener la posibilidad de ser considerada como presunta víctima frente a una denuncia contra el Estado respectivo.

Por su parte, determinando quién es el Estado Denunciado se podría finalmente solventar el problema de saber con certeza si la CIDH seguiría teniendo competencia para adelantar el examen de peticiones individuales, frente a un Estado que ha denunciado la CADH y la Carta de la OEA. Para ello, es necesario ahondar en unas precisiones. En primer lugar, el Estatuto de la Comisión en su artículo 20.b, no contempla competencia alguna para este organismo que le permita adelantar un examen de comunicaciones contra un Estado que no sea miembro de la OEA.

De hecho, si se observa el reglamento de la CIDH en su Capítulo II se ocupa de las peticiones referentes a la CADH y otros instrumentos aplicables y, en su artículo 27 es claro en señalar que, como condición para considerar la petición, las peticiones sobre presuntas violaciones de los derechos humanos se tomarán en consideración, "con relación a los Estados miembros de la OEA". Es decir, que, si un Estado ya no es miembros de la OEA, no podrá ser objeto de esta función, a pesar de que, en razón a la materia, se cumpla el factor de competencia.

En segundo lugar, si se hace una revisión del capítulo III del reglamento de la Comisión, éste se ocupa de los Estados que no son parte de la Convención Americana, señalando que será competente para recibir y examinar peticiones de denuncias sobre las presuntas violaciones de los derechos humanos consagrados en la Declaración Americana de los Derechos y Deberes del Hombre "con relación a los Estados miembros de la Organización que no sean partes en la Convención Americana sobre Derechos Humanos".

Como se puede observar, para el caso del Estado que haya denunciado la Convención Americana y la Carta de la OEA, la Comisión no tendría competencia por el factor Ratione Personae, puesto que es claro que ni su Estatuto ni su reglamento le confieren la posibilidad de examinar peticiones individuales contra un Estado que no sea miembro de la OEA, ya que su competencia en este sentido, se legitima frente al catálogo de derechos de la Convención Americana y otros instrumentos aplicables o en la Declaración Americana de los Derechos y Deberes del Hombre, pero siempre en relación a los Estados miembros de la organización de los Estados Americanos, condición que un Estado que denuncia la Carta de la OEA, perdería una vez entre en vigencia dicha denuncia. En efecto la Corte IDH en su Opinión Consultiva OC-1/82, al interpretar el artículo 64 de la Convención Americana, definió que por “Estados Americanos" debe entenderse, conforme al sentido corriente, que se trata de los Estados que pueden ratificar o adherirse a la CADH, es decir, los miembros de la OEA, membresía o estatus que perdería el Estado que ha denunciado la Carta de la OEA, una vez ésta se haga efectiva (Opinión Consultiva, 1982).

Por lo tanto, la Comisión Interamericana no tendría competencia por el factor Ratione Personae, frente a un Estado que a pesar de ser parte de una Convención Interamericana que otorga competencia a la CIDH para recibir y examinar denuncias individuales en su contra, ha denunciado la Carta de la OEA y deja de tener la consideración de Estado Americano.

Frente a la competencia de la CIDH para recibir y examinar comunicaciones interestatales respecto de los Estados parte de las Convenciones Interamericanas contra toda forma de discriminación e intolerancia y sobre la protección de los derechos humanos de las personas mayores, el legitimado para presentar esta comunicación es cualquier Estado que sea parte de las respectivas Convenciones. Sin embargo, para que un 
Estado parte pueda ser objeto de denuncia interestatal ante la CIDH, es necesario que previamente efectué una declaración, adicional a la ratificación o adhesión a la respectiva convención, en donde señale expresamente que reconoce esta competencia. No obstante, nada señala ninguna de las dos convenciones sobre si el Estado que presenta la denuncia o comunicación debe haber aceptado previamente la competencia ante la Comisión, lo que en principio pareciera indicar que el legitimado por activa para presentar una comunicación interestatal, solo requiere tener la condición de Estado parte de la respectiva Convención.

A pesar de la anterior precisión, no se puede obviar que ambas convenciones remiten a las normas de procedimiento pertinentes contenidas en la Convención Americana, al Estatuto y Reglamento de la Comisión, por lo que se hace necesario remitirse a dichos instrumentos para solventar qué condiciones debe cumplir el Estado que quiera presentar una comunicación interestatal. Es decir, basta con que el Estado sea parte de alguna de las dos Convenciones que prevén la competencia de comunicaciones interestatales o adicional a ello debe haber aceptado mediante declaración dicha competencia, para poder presentar una comunicación contra otro Estado.

Para dilucidar dicho interrogante, es menester remitirse en primer lugar a la CADH en dónde en su artículo 45 se prevé la facultad de que la CIDH reciba y examine comunicaciones interestatales, haciendo referencia a los Estados parte de la Convención, situación que directamente no es aplicable al Estado que haya denunciado la CADH. Sin embargo, es importante resaltar que en la CADH se establece claramente que la Comisión sólo admite este tipo de comunicaciones si son presentadas por un Estado parte que previamente haya reconocido la respectiva competencia. Es decir, admite dichas comunicaciones, atendiendo a una condición de reciprocidad (Steiner \& Fuchs, 2019, pág. 934).

Por su parte, el Estatuto de la Comisión establece en sus artículos 23 y 24 que el reglamento de la CIDH determinará "de acuerdo con lo dispuesto en los artículos 44 al 51 de la Convención Americana sobre Derechos Humanos, el procedimiento que se debe seguir en los casos de peticiones o comunicaciones en las que se alegue la violación de cualquiera de los derechos que consagra la mencionada Convención y en las que se impute tal violación a algún Estado parte en la misma" y así mismo, que establecerá el procedimiento que se debe seguir en los casos de comunicaciones que contengan denuncias o quejas de violaciones de derechos humanos imputables a Estados que no sean partes en la Convención Americana sobre Derechos Humanos" (Asamblea General de la OEA, 1979). Es así como el reglamento de la CIDH estipula en su artículo 50 que la comunicación interestatal, presentada por un Estado parte de la CADH que haya aceptado la competencia de la Comisión para recibir y examinar dichas comunicaciones, deberá ser trasmitida al Estado denunciado, sea que haya aceptado dicha competencia o no. En caso de no haberla aceptado previamente se prevé la posibilidad establecida en el artículo 45, párrafo 3 de la CADH que permite que el Estado reconozca la competencia de la CIDH.

Como se puede observar de las normas a las que remiten las Convenciones Interamericanas, tanto la CADH, el Estatuto y el Reglamento de la Comisión Interamericana, son claras en señalar que para que un Estado parte pueda presentar una comunicación contra otro Estado parte a la Comisión, se requiere: (i) que el Estado que presenta la comunicación sea parte de alguna de las dos Convenciones Interamericanas que en razón a la materia otorgan esta competencia a la CIDH; (ii) que el Estado parte que presenta la comunicación interestatal haya aceptado mediante declaración ésta competencia para ser objeto de comunicaciones por otros Estados parte. Por su lado, para que un Estado pueda ser objeto de comunicación debe: (i) Ser parte de alguna de las dos Convenciones Interamericanas que en razón a la materia otorgan esta competencia a la CIDH y (ii) Haber aceptado previamente mediante declaración esta competencia para ser objeto de comunicaciones por otros Estados parte o, al momento en el que se presente la comunicación en su contra, aceptarla expresamente mediante declaración. 
Si se observan estas precisiones normativas, no es necesario ni que el Estado que presenta la comunicación como el que es objeto de esta, sean parte de la CADH o de la OEA. De esta manera, la competencia de la CIDH para recibir y examinar comunicaciones interestatales de los Estados parte de las Convenciones Interamericanas contra toda forma de discriminación e intolerancia y sobre la protección de los derechos humanos de las personas mayores, se mantendría frente a un Estado parte de estas convenciones que haya aceptado dicha competencia, sin importar si son Estados parte de la CADH o de la OEA. Es decir, la denuncia efectiva de la CADH y de la Carta de la OEA, no conllevan la imposibilidad de que la CIDH pueda seguir ejerciendo su competencia de recibir y examinar comunicaciones interestatales en virtud de las plurimencionadas Convenciones Interamericanas.

En cuanto a la competencia de la CIDH para recibir informes de los Estados parte sobre el cumplimiento de las obligaciones de la Convención Interamericana para prevenir y sancionar la tortura y prestar asesoría y cooperación técnica a los Estados parte de la Convención interamericana sobre la protección de los derechos humanos de las personas mayores, son competencias que se presentan con independencia de que el Estado sea miembro de la OEA. Es decir, dicha competencia se asume como automática frente al Estado, debido a su pertenencia a la respectiva Convención Interamericana.

Sin embargo, no se encuentra clara la lógica de dicho mecanismo de presentación de informes si frente a ese Estado no se puede poner en funcionamiento herramienta alguna en el marco de la OEA, para discutir y mejorar el Estado de protección de las obligaciones interamericanas, como lo puede ser el escenario de la Asamblea General de la OEA, puesto que éste Estado bajo análisis no haría parte de la organización americana, lo que implica que difícilmente va tener algún efecto práctico la presentación de la información, si no se puede ejercer presión política o diplomática a nivel interamericano para lograr que el Estado cumpla con los cometidos de la convención. De hecho, ese es el mandato del artículo 17 de la Convención, cuando señala que la CIDH procurará analizar en su informe anual la situación de los Estados miembros de la OEA, respecto a la prevención y supresión de la tortura.

Este tipo de función de analizar informes que ha sido propia del sistema convencional de Naciones Unidas frente a los Comités, de por si ha sido bastante criticado por su falta de efectividad, por lo cual se considera en el sistema interamericano que, si bien la Comisión tendría competencia para recibir el informe que deba presentar el Estado parte de la Convención, no está clara la competencia para analizar los informes de un Estado que haya denunciado la Carta OEA y la Convención Americana, lo cual en todo caso, si se hace, a nivel práctico sería muy cuestionable frente a los cometidos de la Convención, conforme se señaló en líneas anteriores.

En cuanto a la competencia de la Comisión Interamericana para prestar asesoramiento y cooperación técnica a los Estados parte de la Convención Interamericana sobre la protección de los derechos humanos de las personas mayores y la Convención Interamericana contra toda forma de discriminación e intolerancia, se considera que es una competencia que no presenta mayores problemas frente al factor Ratione Personae, puesto que en el sentido claro de las palabras, la convención prevé la posibilidad de que los Estados parte, soliciten consultas, así como asesoramiento y cooperación técnica a la CIDH, con el propósito de asegurar la aplicación efectiva de las disposiciones de las Convenciones.

Por lo tanto, la competencia clara que mantendría la Comisión Interamericana frente a un Estado que ha denunciado la CADH y la Carta de la OEA, sería la de recibir y examinar comunicaciones interestatales y absolver consultas y prestar asesoría y cooperación técnica a los Estados parte de la Convención interamericana sobre la protección de los derechos humanos de las personas mayores y la Convención Interamericana contra toda forma de discriminación e intolerancia. Lo anterior, atendiendo a que la competencia para 
recibir y examinar peticiones individuales se perdería en razón al factor de competencia Ratione Personae, situación que se predica igualmente del análisis de informes con respecto a la Convención de la tortura.

Es así como, frente a un Estado que denuncia la CADH y la Carta de la OEA, se considera que la CIDH pierde competencia respecto a ese Estado para recibir y examinar peticiones en su contra, así como para hacer monitoreo sobre el cumplimiento de las obligaciones internacionales derivadas de la Declaración Americana. Así que aquellas personas que quieran denunciar alguna violación a sus derechos, no podrán hacerlo contra aquellos Estados que no sean miembros de la organización, ya que ni su Estatuto ni su reglamento le confiere la posibilidad de revisar las peticiones contra estos Estados, situación que en todo caso no se predicaría, respecto de la posibilidad de presentar comunicaciones interestatales en cuanto a los Estados parte de las Convenciones Interamericanas contra toda forma de discriminación e intolerancia y sobre la protección de los derechos humanos de las personas mayores.

\section{Discusiones}

Resulta claro que la denuncia a la Convención Americana no conlleva que de manera automática el Estado deje de ser parte de los demás Convenios Interamericanos que haya ratificado o adherido, los cuales forman parte integral del Sistema Interamericano de Derechos Humanos, pues cada uno de estos instrumentos tienen sus propios mecanismos de denuncia o retiro. Lo anterior, teniendo presente que la denuncia efectiva de la CADH conlleva el retiro del Protocolo de San Salvador, al ser adicional a la Convención. Además, la denuncia de la CADH tampoco afecta el contenido obligacional derivado de la Declaración Americana de Derechos y Deberes del Hombre, ya que el mismo se deriva de su condición de Estado americano miembro de la OEA.

En otro escenario, si entra en vigor tanto la denuncia de la CADH como la denuncia de la Carta de la OEA, tampoco conllevaría a la denuncia o retiro automático de las demás Convenciones Interamericanas sobre Derechos Humanos, en los cuales el Estado denunciante sea parte. Sin embargo, si conllevaría irremediablemente, que la Declaración Americana perdiera su condición de instrumento generador de obligaciones internacionales para el Estado, pues su valor de fuente de obligaciones deriva de manera directa de la Carta de la OEA y la condición del Estado como parte de esta organización, sin perjuicio que las obligaciones en materia de derechos humanos derivadas de la Declaración, sean a su vez lus Cogens, puesto que al ser reconocidas como normas imperativas del derecho internacional, subsisten en su contenido obligacional para el Estado denunciante. Bajo esta perspectiva, el contenido obligacional de la Declaración Americana puede seguir siendo considerado como materialmente vinculante, en cuanto se encuentre en cualquier otra norma de carácter convencional o consuetudinario, que constituyen norma imperativa de derecho internacional o lus Cogens.

Del análisis efectuado es claro que la CIDH pierde competencia respecto al Estado denunciante de la CADH y la Carta de la OEA, para recibir y examinar peticiones individuales en su contra, así como hacer monitoreo sobre el cumplimiento de las obligaciones internacionales derivadas de la Declaración Americana. Sin embargo, si el Estado denunciante es parte de algunas de las Convenciones Interamericanas sobre Derechos Humanos, es factible que la Comisión Interamericana continúe ejerciendo ciertas competencias frente a este Estado.

Dentro de dichas competencias se tiene que la CIDH seguiría teniendo la posibilidad de recibir y examinar denuncias interestatales contra el Estado denunciante, siempre que este sea parte de las Convenciones Interamericanas contra toda forma de discriminación e intolerancia y sobre la protección de 
los derechos humanos de las personas mayores y haya aceptado previamente, mediante declaración esta competencia, o incluso aceptar dicha competencia, en el momento en el que la CIDH le transmite una comunicación en su contra.

A su vez, la Comisión Interamericana podría continuar manteniendo competencias respecto al Estado denunciante, si éste tiene la condición de Estado parte de la Convención interamericana sobre la protección de los derechos humanos de las personas mayores y la Convención Interamericana contra toda forma de discriminación e intolerancia, lo cual conllevaría que la CIDH pudiera absolver consultas y prestar asesoría y cooperación técnica a este Estado.

Respecto de la competencia derivada de la Convención Interamericana para prevenir y sancionar la tortura, para que la CIDH pueda recibir informes de los Estados parte sobre las medidas legislativas, judiciales, administrativas y de otro orden que hayan adoptado en aplicación de esta Convención, se considera que la misma se mantendría frente al Estado denunciante de la CADH y la Carta de la OEA. Sin embargo, no se encuentra efecto práctico a dicha competencia frente a este Estado, debido a que el análisis de esta información se efectúa en el marco de la OEA, frente a los Estados miembros, lo cual evidencia la dificultad de adelantar esta función frente al Estado denunciante, que ya no seria considerado miembro de la OEA.

Como se puede observar, si bien sería un fracaso diplomático la salida de un Estado de la Organización de Estados Americanos, la denuncia efectiva de la Carta de la OEA no implica automáticamente que la Comisión Interamericana como institución de garantía de los Derechos Humanos en la región pierda dicha función frente al Estado denunciante. En cada caso, se debe analizar la situación del Estado no solo frente a la Convención Americana y la Carta de la OEA sino también respecto de cada una de las Convenciones Interamericanas sobre Derechos Humanos, ya que como se pudo apreciar de ellas, se deriva un contenido obligacional a nivel interamericano y se otorgan competencias específicas a la Comisión.

\section{Referencias Bibliografica}

Asamblea General de la OEA. (Octubre de 1979). Estatuto de la Comisión Interamericana de Derechos Humanos. Aprobado mediante la Resolución № 447 adoptada por la Asamblea General de la OEA en su noveno período ordinario de sesiones, celebrado en La Paz, Bolivia, octubre de 1979. Bolivia.

Caso Lagos del Campo Vs. Perú (Excepciones Preliminares, Fondo, Reparaciones y Costas) (Corte Interamericana de Derechos Humanos 31 de Agosto de 2017).

Cebada Romero, A. (1967). LOS CONCEPTOS DEOBLIGACIÓN ERGA OMNES, IUS COGENSY VIOLACIÓN GRAVE A LA LUZ DEL NUEVO PROYECTO DE LA CDI SOBRE RESPONSABILIDAD DE LOS ESTADOS POR HECHOS ILÍCITOS. AJIL.

Comisión de Derecho Internacional. (2018). Normas Imperativas de Derecho Internacional General (Ius Cogens).

Comisión Interamericana de derechos Humanos. (Octubre-Noviembre de 2009). Reglamento de la Comisión Interamericana de Derechos Humanos. Aprobado por la Comisión en su $137^{\circ}$ período ordinario de sesiones, celebrado del 28 de octubre al 13 de noviembre de 2009; y modificado el 2 de septiembre de 2011 y en su 1470 período ordinario de sesiones, celebrado del 8 al 22 de marzo de 2013.

Comisión Interamericana de Derechos Humanos. (2013). Reglamento de la Comisión Interamericana de Derechos Humanos.

Comité de Derechos Humanos. (1997). Comentarios generales adoptados por el Comité de los Derechos Hu- 
manos, Continuidad de las obligaciones 660 período de sesiones.

Corte Interamericana de Derechos Humanos. (2018). Jurisdicción Especial para la Paz. Obtenido de ABC de la Corte Interamericana de Derechos Humanos: https://www.jep.gov.co/Sala-de-Prensa/Documents/ ABCCorteIDH.pdf

Corte Interamericana de Derechos Humanos. (2012). Documentos básicos en materia de Derechos Humanos en el sistema interamericano. San José de Costa Rica, Costa Rica.

Informe n.o 51/96. Personas haitianas. Estados Unidos, Caso 10.675 (Comisión Interamericana de derechos Humanos 13 de Marzo de 1997).

Lopez Hualde, M. C. (s.f.). LA DENUNCIA DE VENEZUELA A LA CONVENCIÓN AMERICANA SOBRE DERECHOS HUMANOS: SU IMPACTO SOBRE EL PROCESO DE FORTALECIMIENTO DEL SISTEMA INTERAMERICANO DE PROTECCIÓN DE DERECHOS HUMANOS. Centro de Estudios Sudamericanos, 1-21.

Opinión Consultiva, OC-1/82 (Corte Interamericana de Derechos Humanos 24 de Septiembre de 1982).

Opinión Consultiva OC-10/89 (Corte Interamericana de Derechos Humanos 14 de Julio de 1989).

Opinión Consultiva OC-22/16 (Corte Interamericana de Derechos Humanos 26 de febrero de 2016).

Organización de Estados Americanos. (30 de Abril de 1948). CARTA DE LA ORGANIZACIÓN DE LOS ESTADOS AMERICANOS. reformada por el Protocolo de Buenos Aires en 1967, por el Protocolo de Cartagena de Indias en 1985, por el Protocolo de Washington en 1992, y por el Protocolo de Managua en 1993. Bogotá, Colombia.

Organización de Estados Americanos. (7-22 de Noviembre de 1969). Convención Americana sobre Derechos Humanos. San José de Costa Rica, Costa Rica.

Organización de Estados Americanos. (2014). Departamento de derecho Internacional. Obtenido de Tratados Multilaterales: https://www.oas.org/dil/esp/tratados_B-32_Convencion_Americana_sobre_Derechos_Humanos_firmas.htm

Organización de Naciones Unidas. (23 de Mayo de 1969). Convención de Viena sobre el derecho de los tratados. U.N. Doc A/CONF.39/27 (1969), 1155 U.N.T.S. 331. Viena, Austria.

Organización de las Naciones Unidas. (2019). Terminología. Obtenido de Definiciones de términos para la base de datos sobre declaraciones y convenciones: https://www.un.org/spanish/documents/instruments/terminology.html

Presidente de la República Bolivariana de Venezuela. (27 de Abril de 2017). Obtenido de http://www.oas.org/ es/sla/ddi/docs/a-41_nota_venezuela_04-28-2017.pdf

Presidente (e) de la República Bolivariana de Venezuela. (8 de Febrero de 2019). Obtenido de http://www. oas.org/es/sla/ddi/docs/a-41_nota_Juan_Guaido_03-7-2019.pdf

Quispe Remon, F. (2012). las normas de ius cogens: ausencia de catálogo. Anuario Español de Derecho Internacional, Vol. 28, 143-183.

Sanchez Gomez, S. (2015). Universidad Carlos III de Madrid. Obtenido de Universidad Carlos III de Madrid: https://e-archivo.uc3m.es/bitstream/handle/10016/22796/estados_sanchez_TFM_2015.pdf?sequence=1\&isAllowed $=y$

Secretaria General de la Organización de Estados Americanos. (1960). Quinta Reunión de Consulta de Ministros de Relaciones Exteriores - Acta Final. Washington: Unión Panamericana.

Salazar Marin, D. (2016). La DenunciadeTratadosInternacionalesde Derechos Humanos. Iurls dlctlo, 75-118.

Steiner, C., \& Fuchs, M.-C. (2019). Convención AMericana sobre Derechos Humanos. KONRAD-ADENAUER-STIFTUNG e. V. 
